\title{
A weighty issue: The implications of an ultrasound prediction of a large baby in pregnancy
}

Cara Baddington ${ }^{A}, B$ PGDip(Mid), RM, BM, LLB, BCA • George Parker ${ }^{B}$ PhD, MPhil, PGDip(Arts), RM, BM

${ }^{A}$ Corresponding

Author: cara.

baddington@op.ac.nz

${ }^{B}$ School of

Midwifery, Otago

Polytechnic, Aotearoa

New Zealand

\begin{abstract}
Introduction: The assessment of fetal growth in Aotearoa New Zealand is governed by a largely medical model of care which highly values the purported objectivity of sonographic assessment. Ultrasound scans are an increasingly normalised part of pregnancy care, and expectant parents may advocate strongly for access to them. It could be questioned whether the increasing number of scans is aligned with clinical need. This paper presents a literature review that explores the implications of an ultrasound diagnosis of a large baby during pregnancy.
\end{abstract}

Method: Databases searched were CINAHL, PubMed, Proquest, and Google Scholar. Search terms used were "macrosomia", "large for dates" and "large for gestational age". This search was first undertaken in May 2019, and then repeated in November 2020.

Findings: Sonographic assessment of fetal size can be inaccurate and the existence of a predicted fetal weight on scan increases the likelihood of birth interventions, regardless of the baby's actual size. While there are potentially negative outcomes associated with a larger baby, it is unclear whether birth interventions will significantly reduce the occurrence of these outcomes. There is limited research that focuses on the parents' experience of having a predicted large baby, offering contradictory insights, which suggests the influence of conflicting meanings applied to large babies and ignoring the experiences of women whose babies were predicted to be large but were born "normal" sized.

Discussion: Midwives are encouraged to openly discuss with women the limitations in available evidence in this area. Midwives can consider the context of the woman and whānau (wider family), and how they may assess risk uniquely. Finally, midwives can honour the woman and whānau as the decision-makers in their own experience. There are further opportunities for research to provide a counter-narrative to medicalising discourses about large babies, grounded in a midwifery belief in normal birth.

Conclusion: Midwives and women are drawn into a risk-centric paradigm that pathologises large babies for questionable benefit. To support informed decision-making within the midwifery partnership, midwives need to critically evaluate existing research and communicate its limitations and risk-centric orientation.

Keywords: macrosomia, large baby, ultrasound, risk, normal birth, informed decision-making

\section{INTRODUCTION}

Ultrasound is now omnipresent in Aotearoa New Zealand (NZ) maternity care. The Ministry of Health $(\mathrm{MOH})$ co-funds two routine ultrasound scans in all pregnancies $(\mathrm{MOH}, 2019 \mathrm{a})$; however, Aotearoa NZ midwives have raised concerns about a culture of expectation around frequent additional routine scans, overuse of scans, and unnecessary social scans (Morris, 2020; New Zealand College of Midwives, 2019). The complexities of ultrasound, as both a medical intervention and a socio-cultural practice, have been well established in the literature (e.g., Frost \& Haas, 2017). Ultrasound is frequently framed and understood as an opportunity to meet the baby and gain reassurance that all is well with the pregnancy (e.g., Thomas \& Lupton, 2016). However, in practice, ultrasound can irrevocably change the clinical pathway of pregnancy and childbirth care as well as expectant parents' confidence, regardless of actual improved birth outcome. Whether a scan is undertaken specifically to obtain an estimation of the baby's size, or whether this is an incidental finding in a scan undertaken for another reason, there is no doubt that the finding of an apparently large baby on ultrasound has significant implications for the childbirth journey (Blackwell et al., 2009; Jarvie, 2016; Peleg et al., 2015; Reid et al., 2014; SadehMestechkin et al., 2008).

This paper presents a literature review that explores the implications for midwifery practice of an ultrasound prediction of a large baby during pregnancy. The literature reveals current limitations in existing evidence relating to the identification and management of predicted large babies and the dominance of riskcentric approaches typical of a medicalised model of maternity care. We begin with a consideration of how large babies are defined and discuss current practices related to prediction of this during pregnancy. We then explore the literature relating to the 
accuracy of an ultrasound estimated fetal weight (EFW), clinical outcomes in the presence of a predicted large baby and women's experiences of this phenomenon. We highlight the dominance of a risk-centric paradigm in existing literature relating to the prediction of a large baby during pregnancy and the resulting maternity care pathways intended to manage them. As a result, large babies are being constituted as a pathology of pregnancy that requires medical surveillance and management. We question the implications of this framing for midwifery practice grounded in normal birth, for the information shared with parents and for their informed decision-making. We conclude by presenting a discussion about current best practice midwifery care, taking into account the limitations of existing evidence and the existing bias towards risk. We affirm the need for further research to support midwifery practice in relation to the care of expectant parents with predicted large babies by making room for a midwifery belief in normal birth and for other cultural understandings about large babies that are de-pathologising.

\section{Rationale for literature review}

Midwifery practice in Aotearoa NZ is grounded in a fundamental belief in normal birth. This includes the belief that normal birth supports optimal outcomes for birthing whānau and that most well women want to, and can, give birth normally (New Zealand College of Midwives, 2009). The midwife is seen as having a key role in protecting the physiological process of pregnancy and birth at all levels of her interaction with birthing whānau (New Zealand College of Midwives, 2009). In the face of rising levels of unnecessary intervention occurring in childbirth, both internationally and in Aotearoa NZ, this increasingly requires midwives to take a critical and questioning stance on existing evidence in support of medical interventions during pregnancy and childbirth (New Zealand College of Midwives, 2009). In particular, midwives need to be alert to the extent to which existing evidence underpinning medical interventions is partial and influenced by a medical paradigm grounded in pathology and risk. Various scholars have observed that risk has become a pervasive feature of a dominant medical paradigm, which has become authoritative and hegemonic in contemporary maternity care (e.g., Chadwick \& Foster, 2014; Davis-Floyd, 2018; Lupton, 2012). The medical model of childbirth promises to predict and minimise risk but, in the process, has redefined childbirth as a medical event, renders a normal event pathological and is argued to have disempowered birthing people (Chadwick \& Foster, 2014). The language of risk as it has become embedded in contemporary childbirth practices emphasises expert and evidence-based knowledge, prediction and control. To minimise risk, childbirth must therefore be managed by experts, constantly monitored and is subject to a series of investigations in order to probe dysfunction and abnormality (Chadwick \& Foster, 2014). Ideas about risk in childbirth are reshaping childbirth but are also socially constructed and threaten a midwifery belief in normal birth. Midwives, therefore, have an important role to play in engaging critically with risk-centric discourses that are implicated in the pathologisation of large babies and other sites of medicalisation. This awareness will help ensure midwives can fulfil our professional responsibility for evidencebased practice alongside, and in tandem with, our belief in normal birth and our professional responsibility to uphold women's right to make informed decisions throughout the childbirth experience (New Zealand College of Midwives, 2009).

The ultrasound prediction of large babies provides a fertile example of the need for midwives to evaluate and engage critically with the evidence underpinning childbirth interventions. In Aotearoa
NZ, midwives' practices in relation to fetal growth assessment are guided by professional frameworks laid out by the New Zealand College of Midwives (the College). As part of the Choose Wisely initiative, the College (2018) recommends that, "in the absence of other clinical concerns ultrasound scans should not be offered routinely to check if a baby is bigger than normal for its gestational age" (para.3). This statement is further clarified in the draft practice guidance Assessment and promotion offetal wellbeing during pregnancy, which does not include fundal height measurements above the 90th percentile in its list of potential growth issues (New Zealand College of Midwives, 2021). Nationally, district health boards are requiring customised growth charts to be used for all pregnant women (Auckland District Health Board, 2015), and the College has suggested a preference for recording fundal height on a customised growth chart (New Zealand College of Midwives, 2021). Customised growth chart protocols themselves do not suggest that an ultrasound scan is necessary for a fundal height measurement over 90th centile (Perinatal Institute for Maternal and Child Health, 2020). However, the MOH's Guidelines for Consultation with Obstetric and Related Medical Services (Referral Guidelines) direct midwives to offer referral for obstetric consultation where there is an EFW on a customised growth chart that is greater than the 90th percentile (MOH, 2012). Midwives themselves acknowledge an increasing reliance on ultrasound scans, while at the same time questioning their accuracy and expressing reservations about the increasing medicalisation of pregnancy through reliance on technology (Morris, 2020).

The rationale for pregnancy ultrasound scans is to identify anomalies in order to improve pregnancy and childbirth outcomes through responsive care $(\mathrm{MOH}, 2019 \mathrm{a})$. However, concern has been expressed by government maternity advisors that pregnancy ultrasound numbers are increasing and that a scan may at times be performed without clinical need (National Maternity Monitoring Group, 2015). Further, it is recognised that there is an increase in birth interventions nationally (MOH, 2019b). A consideration of the literature in relation to ultrasound scans and birth outcomes may illuminate the question of whether an increase in ultrasound scans may contribute to an increase in interventions.

Women also bring their own set of meanings and expectations to pregnancy ultrasound scans, beyond those intended in clinical care. These meanings are shaped by the social, cultural, and political implications of technologically mediated pregnancies, that reconfigure the relationship between pregnancy, the fetus, and society (Lupton, 2012; Taylor, 2008; Thomas \& Lupton, 2016). Ultrasound scans have been shown to hold significance for expectant parents as an opportunity to meet and bond with their babies, to be reassured about the progress of their pregnancies and to connect with family and friends throughout the transition to parenthood (Mitchell, 2004; Taylor, 2008). Expectant parents frequently strongly advocate for access to scans during pregnancy (Thomas et al., 2017).

However, while ultrasound technologies have been embraced as a social-cultural practice, they are not benign. Critical midwifery and feminist scholars have pointed to the ways in which ultrasound scans can disembody and disempower pregnant people, increase vulnerability to surveillance and control, induce anxiety in expectant parents, and medicalise otherwise normal and healthy pregnancies (Frost \& Haas, 2017; Lupton, 2012; Mitchell, 2004; Roberts, 2012; Taylor, 2008; Thomas et al., 2017). Where there is a growing level of technological monitoring, there comes an increased awareness and decision-making around management of risk. This greater discussion of risk encourages greater dependence 
on technology and undermines low intervention approaches that are the focus of midwifery care (Lupton, 2012; Van Wagner, 2016).

The clinical, socio-cultural and political implications of pregnancy ultrasound scans form an important backdrop to health professionals' recommendations and women's decision-making around a prediction of a large baby in pregnancy. Ultrasound scans are an increasingly normalised and expected part of pregnancy care and, as a result, are identifying variations in fetal size in greater numbers. It is therefore timely to understand the implications of a large baby prediction for care pathways as well as the experiences of expectant parents. This can help inform and support holistic midwifery care in this context.

\section{METHOD}

For each aspect of the review, a number of databases were searched (CINAHL, PubMed, Proquest, and Google Scholar), and references for relevant papers were also hand searched. This search was first undertaken in May 2019, and then repeated in November 2020. Search terms included "macrosomia", "large for dates" and "large for gestational age". Further specific search terms relating to the subsequent sub sections were: fetal weight estimation, ultrasound, accuracy, risk, outcome, complications, women, pregnant people, experiences and perceptions. A broad date range from 1995 to 2020 was chosen. Papers that were published in a language other than English were excluded.

\section{FINDINGS}

This section reviews literature relating to how large babies are clinically defined (macrosomia), the accuracy of EFW by scan in the diagnosis of macrosomia, potential clinical outcomes for mothers and babies and, finally, parents' experiences of a prediction of a large baby and the resulting care pathways. Note that we have chosen to use the term "large babies" except where specifically discussing research findings that reference macrosomia, as we believe that the clinical term macrosomia is value-laden with a pathological view of large babies. "Large" or "big" themselves are not value free but lack the same extent of medicalising stigma as macrosomia. Note also that while we refer to "women", we acknowledge that not all people who are pregnant and give birth are women and we recognise gender-diverse pregnant people as consumers of maternity care.

\section{Assessing babies for largeness in pregnancy}

The clinical term macrosomia is used to describe a large baby. There are inconsistencies in how the literature defines macrosomia, with definitions largely varying between a birthweight of greater than either 4000g or 4500g (Colman et al., 2006; Ray \& Alhusen, 2016). In Aotearoa NZ, reporting by the district health boards and the $\mathrm{MOH}$ focuses on the latter, the justification for which is not clear. In 2017, 2.4\% of babies were $4500 \mathrm{~g}$ or greater at birth (MOH, 2019b). Other terminology that is frequently used in this space is "large for gestational age" which is defined as a baby having an EFW above the 90th customised percentile (New Zealand College of Midwives, 2021).

The actual size of the baby, whether large or small, can only be confirmed once the baby is born. However, providers of antenatal care place great importance on the estimation of fetal size, particularly regarding identifying smaller babies, who are at greater risk of poor outcomes such as intrauterine growth restriction and stillbirth (Figueras \& Gardosi, 2011; Stacey et al., 2011). Three main methods for estimating fetal size during pregnancy are described in the literature: clinical (palpation and fundal-symphysis height measurement), maternal estimation and sonographic assessment, with each having their own limitations (Ray \& Alhusen, 2016). Abdominal palpation and maternal estimation both rely heavily on the subjective experience of either the midwife or the mother, and can therefore occupy a more marginal status in fetal size estimation (Morris, 2020). Very limited research has explored the utility of maternal estimation (embodied knowledge) in assessing fetal size, suggesting a devaluing of women's own embodied experiences as part of clinical assessment in antenatal care (Chauhan et al., 1992; Morris, 2020; O'ReillyGreen \& Divon, 2000). Inversely, ultrasound is positioned as an objective, and therefore more accurate, approach to the assessment of fetal size. There is a tension between the clinical and the social meanings applied to ultrasound, in that ultrasound is considered objective and accurate, but the reality is that ultrasound uses biometric measurements to predict weight. Such measurements can only ever be just that - a prediction, i.e., not necessarily accurate.

We will now discuss the complexities (and limitations) of the use of ultrasound for the estimation of fetal weight, as identified in the literature.

\section{Estimating fetal weight: complexities}

A number of studies have found that the use of ultrasound for the estimation of fetal weight is substantially inaccurate, particularly for larger babies (e.g., Chauhan et al., 2005; Colman et al., 2006; Milner \& Arezina, 2018; Peregrine et al., 2007; Stubert et al., 2018). Chauhan et al. (2005) reviewed 20 papers that calculated the sensitivity and specificity of an ultrasound estimation of fetal weight of $4000 \mathrm{~g}$ or greater. They found that while scans' ability to correctly predict normal-sized babies in uncomplicated pregnancies (specificity) was relatively high (68\%-99\%), the ability to correctly predict larger babies (sensitivity) was much lower (12\%-75\%). Peregrine et al. (2007) found that sensitivity for predicting large babies was $40 \%-48 \%$ whereas specificity for predicting normal-sized babies is much higher (76\%-83\%).

A local retrospective study undertaken in Aotearoa NZ found that $75 \%$ of EFWs were within $10 \%$ of actual birthweight but that, for $25 \%$ of women, the margin of error was greater than $10 \%$. For $3 \%$ of women, the margin of error was greater than $20 \%$ (Colman et al., 2006). This study affirmed that there is "no formula for estimating fetal weight [that] has achieved an accuracy which enables us to recommend its use" (Colman et al., 2006, p. 6). More recently, Stubert et al. (2018) examined early labour ultrasound in a German hospital. They found that the EFW was within a $10 \%$ margin of error in $72.2 \%$ of cases (and only $45.2 \%$ where the scan was undertaken by a less experienced doctor). EFW was more frequently overestimated in smaller babies and underestimated in larger babies. Despite the study embracing a very medicolegal approach, noting the possible forensic relevance of EFW in the case of birth-related damage and subsequent litigation, it concluded that EFW at term was not reliable for the prediction of macrosomic babies, and should not be recommended.

How this information is presented to families has the potential to greatly affect their experiences and decision-making process. Ray and Alhusen (2016) describe a case study in which a woman underwent a scan which reported an EFW of $4500 \mathrm{~g}$ at term. She was advised to have an elective caesarean due to risks to herself and her baby of planning a vaginal birth. She duly agreed, gave birth to a $3800 \mathrm{~g}$ baby by caesarean, and suffered some distress about whether this was a necessary intervention. This review stressed the importance of open communication and shared decision-making, considering both the inaccuracy of the EFW method and the risks inherent in both caesarean births and inductions. Despite this, 
women who undergo late pregnancy scans in Aotearoa NZ may still be offered the diagnosis of macrosomia based on a predicted fetal weight (Horizon Radiology, personal communication, February 1, 2019).

\section{Clinical outcomes}

Any search for literature on large babies reveals a surfeit of quantitative-based, obstetric-dominated analyses that uncritically describe the clinical outcomes associated with a diagnosis of macrosomia. These studies problematise larger babies and position them as a pathology of pregnancy. Macrosomia is associated with a range of poor obstetric outcomes, including higher rates of shoulder dystocia, brachial plexus injuries, low Apgar scores, admission to special care units and neonatal asphyxia (e.g., Jolly et al., 2003; King et al., 2012; Mocanu et al., 2000; Zhang et al., 2008). Women are described as more likely to experience prolonged labour, assisted vaginal birth, emergency caesarean, third degree perineal tears and postpartum haemorrhage (Jolly et al., 2003; Mocanu et al., 2000; Zhang et al., 2008).

While it is important for both midwives and women to understand the potential negative outcomes that may arise with a larger baby, it is possible to take a more critical approach to the centering of risk in the existing evidence related to macrosomia (Bacchi, 2012). A critical approach allows midwives to consider the ways in which medical knowledge about babies' size is not entirely objective and value free, and may only reflect a partial story about the relationship between EFW and birth outcomes (Bacchi, 2012). Studies pointing to the poor outcomes associated with macrosomia sit within a framework where the mere presence of an EFW (regardless of actual birthweight) has been shown to increase the likelihood of interventions. Stubert at al. (2018) found that the existence of an EFW increased the likelihood of an abnormal cardiotocography (CTG) finding, an obstructed labour finding, and an emergency caesarean. This was regardless of the actual size of the baby the woman gave birth to. They hypothesised that the obstetricians were hyper alert to deviations of labour and seeking an indication to perform a caesarean following the estimation of fetal weight. Another study also found that when there was an EFW of $4000 \mathrm{~g}$ to $4500 \mathrm{~g}$, the caesarean rate was two to two-anda-half times higher, regardless of actual birthweight (Melamed et al., 2010). A recent systematic review found that EFW predicting a large baby does not have a clinically significant effect on successfully predicting shoulder dystocia (Moraitis et al., 2020), with one study identifying numbers needed to treat, which can provide more tangible information for helping communicate the uncertainty surrounding EFW and poor outcomes. This study focused on the outcome of permanent brachial plexus injury as more clinically significant than shoulder dystocia, or maternal injuries from shoulder dystocia, which both tended to be short term in regard to consequences for mother and baby (Rouse et al., 1996). They found that for each potential permanent brachial plexus injury prevented by a policy of planned caesarean with an EFW of greater than $4500 \mathrm{~g}, 443$ caesareans were performed on diabetic women, and 3695 caesareans on non-diabetic women. For comparison, a 2018 Canadian study found that 135 repeat caesareans would need to be performed to avoid one case of uterine rupture including scar dehiscence, or 372 to avoid a case of uterine rupture not including dehiscence (Joseph et al., 2018).

When assimilating data on complications, it is important to consider those studies that have found no improvement in outcomes despite preventative interventions. Stubert et al. (2018) found that even with an increased rate of caesarean birth for suspected macrosomia, short term fetal and maternal morbidities were not improved. Another study compared outcomes for women with correctly predicted macrosomia and those with unsuspected macrosomia and found that the likelihood of caesarean was nine times higher for women with a correctly estimated macrosomic baby than for those where it was not predicted (Peleg et al., 2015). Importantly, there was no commensurate decrease in the rate of shoulder dystocia despite the increase in the number of caesareans (Peleg et al., 2015).

Other studies have found that induction of labour and planned caesarean showed no decrease in shoulder dystocia, and that induction resulted in a higher rate of caesareans with no improvement in perinatal outcomes (Pundir \& Sinha, 2009; Sanchez-Ramos et al., 2002). It is barely mentioned in much of the literature, but we must acknowledge the hidden group of people who may be impacted by recommendations to undertake interventions where a large baby is predicted but does not eventuate. The nature of this retrospective diagnosis means that these women may have been exposed to unnecessary interventions, which carry their own risks, for no possible improvement in outcome (Ray \& Alhusen, 2016).

\section{Women's experiences and informed decision-making}

This lack of certainty about the benefits of obtaining a prediction of a large baby is amplified when insight into parents' experiences of a macrosomia is added to the mix. There is very limited research that has asked how expectant parents are affected by being told they are carrying a large baby, and what does exist is restricted to women who have been confirmed postnatally to have a large baby. There is no exploration of the experiences of whānau Māori (the indigenous people of Aotearoa NZ), and there are no Aotearoa NZ-based studies. The experiences of those people who were incorrectly predicted to be carrying a large baby have also not been considered at all in research to date, which is a significant gap in the literature.

A key piece of existing research on women's experiences by Reid et al. (2014) asked women postnatally about their experiences of receiving a diagnosis of macrosomia during their pregnancies. This Northern Ireland study was a qualitative interview-based study of eleven women. Ten out of the eleven women were multiparous, and the sample was purposively selected with a 50/50 split of caesarean and vaginal birth. Key findings included uncertainty around whether baby was large or not (and some women felt their own predictions around this were ignored), both fear and calm about the impending birth, and a notable lack of control around their input into planning for birth. There was no specific mention of place of birth; however, women noted a sense of fear and anxiety particularly around the size of the baby and proposed mode of birth. Women also experienced challenging antenatal symptoms relating to the size of their babies and had concerns about birth trauma. Regarding their interactions with health professionals, women experienced both positive and negative interactions, valuing the professionalism of their caregivers but at other times not feeling listened to, with little voice in decision-making.

The study also explored women's perceptions around macrosomia itself. Women generally felt positively about their large babies. Perhaps influenced by the activity/nutrition goals of the larger cohort study and an uncritical approach in which the authors took up obstetric discourses unquestioningly, the analysis implied that women were wrong to feel positively about the size of their large babies and should instead feel culpable due to their poor lifestyle habits. The study did acknowledge uncertainty in predicting birthweight and encouraged women to be a part of the decision- 
making process; however, the study authors failed to question their own assumptions about large babies, nor did they acknowledge the power imbalances that may be present in decision-making in the presence of a macrosomia. By deploying the idea that women are wrong to feel positively about their large babies and are culpable for them, the study authors also held true to the tradition of mother blaming that is prevalent in Western healthcare discourses (Jackson \& Mannix, 2004). Mothers and, increasingly, pregnant women are held responsible for the well-being of the children, including the maladjustment of their children, in ways that fathers are not and without regard to the context and circumstances of their lives (Jackson \& Mannix, 2004).

By contrast, Jarvie (2016) used a critical/constructivist paradigm to look at the multiple discourses around shifts in values relating to large babies. The study considered the shifting societal values around large babies; what was once considered a "bonny" healthy baby, regarding a robust birthweight, now draws clinical attention. The authors argue that the trend in problematising large babies is informed by concerned dialogue around obesity, maternal nutrition, genetic programming of metabolism in utero, and the ever-undesirable label of "fatness" (Jarvie, 2016; Parker \& Pausé, 2018).

The study identified two main discourses (medical and popular media) linking macrosomia to maternal responsibility and explored the experiences of a much more diverse sample of 30 women. It acknowledged the impact of these discourses and the power of language in constructing women who birthed large babies as bad mothers, something the women were acutely aware of. The women described an intense focus on their behaviours and consumption practices during pregnancy and felt positioned as individually responsible and to blame for carrying a large baby. They described being more concerned about this stigmatisation and its effects, rather than any particular health concerns about their babies and considered that for the most part they, their babies and their pregnancies were healthy.

Importantly, women were not simply passive recipients of oppressive medicalised meanings about macrosomia. They used a number of strategies to resist the dominant discourse that frames women as neglectful and careless in pregnancy. Women constructed an alternative narrative for themselves including the role of genetics in fetal largeness, assertion of a healthy diet, absence of diabetes, a generally larger population, and a preference for a larger rather than smaller baby. The women also reflected on scaremongering by health professionals ruining their pregnancies.

Two further studies offer a fairly narrow obstetric view of women's experiences of a diagnosis of macrosomia which can be critiqued from a midwifery standpoint (Heery et al., 2013; Vercellini et al., 2015). Both studies reproduce the problematisation of large babies as a pathology of pregnancy, assume obstetric management as standard practice, and engage women's perspectives only as a way of refining rather than questioning medical management approaches. As part of a wider study looking at the relationship between excessive weight gain in pregnancy and macrosomia, Heery et al. (2013) observed that women did not adequately fear the consequences of a diagnosis of macrosomia. Indeed Heery et al. (2013) were critical of women's positive feelings about the health of their babies, and their reluctance to alter their lifestyle habits (diet and exercise patterns) that may have influenced the size of their babies in utero. As with Reid et al. (2014), Heery et al. (2013) default to a position of mother blame, positing pregnant women who gain weight and/or are carrying large babies as neglectful of their maternal responsibilities and to blame for the consequences.
There is a level of paternalism about women's perceptions and understandings of their pregnant bodies and babies in this study that is troubling from a midwifery standpoint.

Vercellini et al. (2015) undertook a quantitative study in an Italian tertiary hospital of around 500 women, aiming to measure satisfaction with the birth of a macrosomic baby. The study concluded that women with macrosomic babies planning a vaginal birth were significantly less satisfied with their birth experience $(67 \%$ in vaginal birth group, $69 \%$ in caesarean in labour group, and $89 \%$ in planned caesarean group). The study boldly concluded that women should be informed of a reduced likelihood of satisfaction when planning a vaginal birth following diagnosis of a macrosomic baby. The study context was difficult to relate to Aotearoa NZ, undertaken as it was in a hospital where all women were routinely given epidurals and episiotomies, and with a much higher assisted birth rate. Further, the data neither dissatisfied or satisfied were classified into the dissatisfied cohort. There was also a failure by the study's authors (as in many others) to consider the experiences/satisfaction of mothers suspected to be carrying a large baby who, in fact, were not.

\section{DISCUSSION}

It is clear from this review of the literature, that the labelling of babies as macrosomic in utero has implications both for the experiences of expectant parents and for their care pathways. We have identified a number of midwifery practice considerations that may assist midwives in working with women in this situation.

Firstly, we have identified the need for an open discussion with women about what evidence is available and any limitations inherent in it. In Aotearoa NZ, midwives are ideally placed in their partnership with women to undertake this. This discussion will need to cover the ways in which midwives and obstetricians estimate fetal growth, and the limitations inherent in these methods. This may be particularly challenging for women as it can often be assumed that ultrasound scanning is an exact science (Ray \& Alhusen, 2016). Midwives must be clear that an EFW is purely a prediction and that although a quoted margin of error is commonly given as $10 \%$, in fact as many as one in four scans will have a higher margin of error than that. Furthermore, midwives also need to ensure women are informed about the possibility of complications with a larger baby, but within the difficult context that the interventions that may be proposed (such as early induction or elective caesarean) do not guarantee improvement in the outcome for mother or baby and do carry their own risks. Midwives have an important role in discussing the benefits of normal birth so that this can be included in the information to be weighed up by the woman.

Secondly, midwives need to consider that women and whānau will assimilate this information in their own way and may assess risk differently (to either the midwife or other families). Women must be seen as situated within their own individual context. That may include things such as their previous birthing histories, their cultural perspectives, whānau perspectives and/or experiences of large babies, the presence of complications such as diabetes, the women's own views on the experience, and how they assess/ balance risk. This will include consideration of the ways that this phenomenon may be experienced by wāhine Māori (Māori women) and how cultural context may be relevant. As highlighted in the review of literature, there is currently no research that considers the experiences of parents within an Aotearoa NZ context and, as such, no research on the experiences of Māori whānau. However, we hypothesise that the prediction of a large baby may disproportionately affect Māori whānau. Māori are more likely to 
be labelled as obese and as "high risk" (MOH, 2019b; Ratima \& Crengle, 2013), and being overweight/obese pre-pregnancy is a risk factor for macrosomia (Dai et al., 2018). Wāhine Māori are also more likely to birth in primary units (Ratima \& Crengle, 2013) and so may also be disproportionately affected by facility criteria that preclude bookings for suspected large-for-dates babies (Capital and Coast District Health Board, 2019). And finally, but not least importantly, midwives should honour women's decisionmaking sovereignty in the midwifery partnership. Reid et al. (2014) noted that women reported not being listened to and feeling that they had no voice in decision-making about birth. This highlights the importance of placing the woman in the role as decisionmaker and not seeking to take away any of her power in living and directing this experience. The Code of Health and Disability Services Consumers' Rights mandates the role of health consumer as decision-maker, and this is also captured in the midwifery partnership model (Guilliland \& Pairman, 2010; Health and Disability Commission, 2020). Reid at al. (2014) discussed the importance of women feeling valued and part of decision-making; however, we would argue that this would represent something of a token approach to informed decision-making and, in fact, the final decisions regarding choices such as place of birth, timing of labour and mode of birth remain with the woman, as supported by our professional midwifery frameworks. Honouring the woman also means avoiding stigmatising the woman or the baby, where there is a prediction of macrosomia, and affirming the woman in her ability to grow and birth her baby.

What little research there is on the experience of an ultrasound prediction of a large baby leaves plenty of room for further exploration and development of midwifery knowledge. There is a need for further research that can guide midwives on how best to communicate the nuances of "evidence" and "risk" with women. This will help ensure that whānau decisions are informed by an accurate understanding of the limitations of ultrasound technology in estimating fetal weight and the questionable ability of medical interventions to improve outcomes for themselves and their babies. Research undertaken in an Aotearoa NZ context will help inform midwives working with the unique aspects of Aotearoa NZ whānau, both Māori and non-Māori.

Midwives also need access to research that provides a counternarrative to dominant risk-centric medical discourses about large babies by making visible the experiences of women who have had positive experiences of carrying and birthing large babies. This needs to include attention to the experiences of that hidden group of women - those who live through the consequences of a prediction of a large baby and then birth a normal-sized baby. Barring one study (Jarvie, 2016), all the research explored in this review was informed by an obstetric paradigm that assumes the growth of large babies as pathological and grounds solutions in the assumption of medical management and intervention as beneficent. We suggest it is necessary and timely to begin to disrupt the dominance of obstetric understandings of large babies. Midwives need an evidence base informed by, and contributing to, midwifery knowledge grounded in normality, partnership, shared decision-making, and empowerment.

\section{CONCLUSION}

In summary, this literature review has raised important questions about the existing evidence base for a medically interventionist approach to predicted large babies during pregnancy, with important implications for midwifery practice. We have demonstrated limitations and inconsistencies in the literature related to macrosomia and pointed to the orientation of existing literature as being towards a risk-based paradigm that is dominant in contemporary maternity care, yet often times inconsistent with a midwifery belief in normal birth. We suggest that midwives need to support families with a critical engagement with the existing evidence related to macrosomia. This means supporting families to question the pathologisation of large babies and to question the benefits of medicalised management and intervention in the face of a prediction of macrosomia. Furthermore, existing knowledge suggests that scan prediction of large babies can be erroneous, emphasising the need for women to have accurate information about the efficacy of scans, the actual risks of having a large baby, and the likelihood of interventions improving birth outcomes. Given the potential disproportionate impact of this issue on Māori wāhine, current practices are also an equity issue for maternity services. Evidence grounded in midwifery paradigms of birth that normalise the range of women's experiences is urgently needed.

\section{CONFLICT OF INTEREST DISCLOSURE}

The authors declare that there are no conflicts of interest.

\section{Key points}

- Evidence regarding ultrasound prediction of large babies in pregnancy is inconsistent and weighted towards a risk-centric medical model of care.

- Drawing on a midwifery belief in normal birth and professional responsibility for informed decisionmaking, midwives need to critically evaluate the current evidence and practices related to macrosomia.

- This will help to ensure that midwives can support informed decision-making within the midwifery partnership when there is a prediction of a large baby in pregnancy.

\section{REFERENCES}

Auckland District Health Board. (2015). Customised antenatal growth chart. https://nationalwomenshealth.adhb.govt.nz/assets/Womenshealth/Documents/Policies-and-guidelines/Customised-AntenatalGrowth-Chart-.pdf

Bacchi, C. (2012). Why study problematizations? Making politics visible. Open Journal of Political Science, 02(01), 1-8. https://doi. org/10.4236/ojps.2012.21001

Blackwell, S. C., Refuerzo, J., Chadha, R., \& Carreno, C. A. (2009). Overestimation of fetal weight by ultrasound: does it influence the likelihood of cesarean delivery for labor arrest? American Journal of Obstetrics and Gynecology, 200(3), 340.e1-340.e3. https://doi. org/10.1016/j.ajog.2008.12.043

Capital and Coast District Health Board. (2019). Policy: Booking criteria and administration process for birthing at Kenepuru/Paraparaumu primary birthing facilities.

Chadwick, R. J., \& Foster, D. (2014). Negotiating risky bodies: childbirth and constructions of risk. Health, risk \& society, 16(1), 68-83.

Chauhan, S. P., Lutton, P. M., Bailey, K. J., Guerrieri, J. P., \&

Morrison, J. C. (1992). Intrapartum clinical, sonographic, and parous patients' estimates of newborn birth weight. Obstetrics and Gynecology, 79, 956-958 
Chauhan, Suneet P., Grobman, W. A., Gherman, R. A., Chauhan, V. B., Chang, G., Magann, E. F., \& Hendrix, N. W. (2005). Suspicion and treatment of the macrosomic fetus: A review. American Journal of Obstetrics and Gynecology, 193(2), 332-346. https://doi.org/10.1016/j. ajog.2004.12.020

Colman, A., Maharaj, D., Hutton, J., \& Tuohy, J. (2006). Reliability of ultrasound estimation of fetal weight in term singleton pregnancies. The New Zealand Medical Journal, 119(1241), U2146. https://doi. org/10.7810/9780947492588_1

Dai, R., He, X., \& Hu, C. (2018). Maternal pre-pregnancy obesity and the risk of macrosomia: a meta-analysis. Archives of Gynecology and Obstetrics, 297, 139-145. https://doi.org/doi.org/10.1007/s00404-0174573-8

Davis-Floyd, R. (2018). Ways of knowing about birth: Mothers, midwives, medicine, and birth activism. Waveland Press.

Figueras, F., \& Gardosi, J. (2011). Intrauterine growth restriction: new concepts in antenatal surveillance, diagnosis, and management. American Journal of Obstetrics and Gynecology, 204(4), 288-300.

Frost, E. A., \& Haas, A. M. (2017). Seeing and knowing the womb: A Technofeminist Reframing of Fetal Ultrasound toward a Decolonization of Our Bodies. Computers and Composition, 43, 88-105. https://doi. org/10.1016/j.compcom.2016.11.004

Guilliland, K., \& Pairman, S. (2010). The midwifery partnership: A model for practice (2nd ed.). New Zealand College of Midwives.

Health and Disability Commission. (2020). Code of Health and Disability Services Consumers' Rights. https://www.hdc.org.nz/your-rights/ about-the-code/code-of-health-and-disability-services-consumers-rights/ Heery, E., McConnon, Á., Kelleher, C. C., Wall, P. G., \& McAuliffe, F. M. (2013). Perspectives on weight gain and lifestyle practices during pregnancy among women with a history of macrosomia: A qualitative study in the Republic of Ireland. BMC Pregnancy and Childbirth, 13, 1-11. https://doi.org/10.1186/1471-2393-13-202

Jackson, D., \& Mannix, J. (2004). Giving voice to the burden of blame: A feminist study of mothers' experiences of mother blaming. International Journal of Nursing Practice, 10(4), 150-158. https://doi. org/10.1111/j.1440-172X.2004.00474.x

Jarvie, R. (2016). "Obese" "sumo" babies, morality and maternal identity. Women's Studies International Forum, 54, 20-28. https://doi. org/10.1016/j.wsif.2015.10.004

Jolly, M. C., Sebire, N. J., Harris, J. P., Regan, L., \& Robinson, S. (2003). Risk factors for macrosomia and its clinical consequences: A study of 350,311 pregnancies. European Journal of Obstetrics and Gynecology and Reproductive Biology, 111(1), 9-14. https://doi. org/10.1016/S0301-2115(03)00154-4 LK

Joseph, K. S., Shiliang, L., Muraca, G. M., Sabr, Y., Pressey, T., \& Liston, R. M. (2018). Mode of delivery after a previous cesarean birth, and associated maternal and neonatal morbidity. Canadian Medical Association Journal, 190(18), e556-e564. https://doi.org/10.1503/ cmaj. 170371

King, J. R., Korst, L. M., Miller, D. A., \& Ouzounian, J. G. (2012). Increased composite maternal and neonatal morbidity associated with ultrasonographically suspected fetal macrosomia. Journal of MaternalFetal and Neonatal Medicine, 25(10), 1953-1959. https://doi.org/10.310 9/14767058.2012.674990

Lupton, D. (2012). "Precious cargo": Foetal subjects, risk and reproductive citizenship. Critical Public Health, 22(3), 329-340. https:// doi.org/10.1080/09581596.2012.657612

Melamed, N., Yogev, Y., Meizner, I., Mashiach, R., \& Ben-Haroush, A. (2010). Sonographic prediction of fetal macrosomia: The consequences of false diagnosis. Journal of Ultrasound in Medicine, 29(2), 225-230. https:// doi.org/10.7863/jum.2010.29.2.225

Milner, J., \& Arezina, J. (2018). The accuracy of ultrasound estimation of fetal weight in comparison to birth weight: A systematic review. Ultrasound, 26(1), 32-41. https://doi.org/10.1177/1742271X17732807

Ministry of Health. (2012). Guidelines for Consultation with Obstetric and Related Medical Services (Referral Guidelines).

Ministry of Health. (2019a). New Zealand Obstetric Ultrasound Guidelines. https://www.health.govt.nz/publication/new-zealandobstetric-ultrasound-guidelines

Ministry of Health. (2019b). Report on Maternity 2017. https://doi.org/ ISBN 978-0-578-40216-2

Mitchell, L. M. (2004). Women's experiences of unexpected ultrasound findings. Journal of Midwifery and Women's Health, 49(3), 228-234.

https://doi.org/10.1016/s1526-9523(03)00490-2
Mocanu, E. V., Greene, R. A., Byrne, B. M., \& Turner, M. J. (2000) Obstetric and neonatal outcome of babies weighing more than $4.5 \mathrm{~kg}$ : An analysis by parity. European Journal of Obstetrics Gynecology and Reproductive Biology, 92(2), 229-233. https://doi.org/10.1016/S03012115(99)00280-8

Moraitis, A. A., Shreeve, N., Sovio, U., Brocklehurst, P., Heazell, A. E. P., Thornton, J. G., Robson, S. C., Papageorghiou, A., \& Smith, G. C. (2020). Universal third-trimester ultrasonic screening using fetal macrosomia in the prediction of adverse perinatal outcome: A systematic review and meta-analysis of diagnostic test accuracy. PLoS Medicine, 17(10), e1003190. https://doi.org/10.1371/journal. pmed. 1003190

Morris, S. (2020). In good hands: Lead maternity carer midwives and fetal growth assessment in Aotearoa New Zealand [Master's thesis, Otago Polytechnic]. Otago Polytechnic Research Repository. https://www. op.ac.nz/industry-and-research/research/postgraduate-studies/oprestheses/midwifery-theses/morris/

National Maternity Monitoring Group. (2015). Annual Report 2015: National Maternity Monitoring Group. http://www.health.govt.nz/ system/files/documents/publications/national-maternity-monitoringgroup-annual-report-2015-dec15.pdf

New Zealand College of Midwives. (2009). Consensus statement: Normal birth. https://www.midwife.org.nz/wp-content/uploads/2019/05/ Normal-Birth.pdf

New Zealand College of Midwives. (2018). Choose wisely. https://www. midwife.org.nz/wp-content/uploads/2018/09/Choosing-Wisely-1.pdf

New Zealand College of Midwives. (2019). Ministry of Health New Zealand obstetric ultrasound guidelines 2019: Consultation feedback from New Zealand College of Midwives. https://www.midwife.org.nz/ wp-content/uploads/2019/05/Obstretric-ultrasound-guidelinesMay-2019.pdf

New Zealand College of Midwives. (2021). Practice guidance document: Assessment and promotion of fetal wellbeing during pregnancy [Draft]. O'Reilly-Green, C., \& Divon, M. (2000). Sonographic and clinical methods in the diagnosis of macrosomia. Clinical Obstetrics and Gynecology, 43(2), 309-320. https://doi.org/10.1097/00003081200006000-00008

Parker, G., \& Pausé, C. (2018). Pregnant with possibility: Negotiating fat maternal subjectivity in the "War on Obesity." Fat Studies, 7(2), 124134. https://doi.org/10.1080/21604851.2017.1372990

Peleg, D., Warsof, S., Wolf, M. F., Perlitz, Y., \& Ben-Shachar, I. (2015). Counseling for fetal macrosomia: An estimated fetal weight of $4,000 \mathrm{~g}$ is excessively low. American Journal of Perinatology, 32(1), 71-74. https:// doi.org/10.1055/s-0034-1376182

Peregrine, E., O’Brien, P., \& Jauniaux, E. (2007). Clinical and ultrasound estimation of birth weight prior to induction of labor at term. Ultrasound in Obstetrics and Gynecology, 29(3), 304-309. https://doi. org/10.1002/uog.3949

Perinatal Institute for Maternal and Child Health. (2020). Growth Assessment Protocol (GAP). November 2020. http://www.perinatal.org.uk/ GAP/GAP.aspx

Pundir, J., \& Sinha, P. (2009). Non-diabetic macrosomia: An obstetric dilemma. Journal of Obstetrics and Gynaecology, 29(3), 200205. https:// doi.org/10.1080/01443610902735140

Ratima, M., \& Crengle, S. (2013). Antenatal, labour, and delivery care for Māori: Experiences, location within a lifecourse approach, and knowledge gaps. Pimatisiwin: A Journal of Aboriginal and Indigenous Community Health, 10(103), 353-366.

Ray, E. M., \& Alhusen, J. L. (2016). The Suspected Macrosomic Fetus at Term: A Clinical Dilemma. Journal of Midwifery and Women's Health, 61(2), 263-269. https://doi.org/10.1111/jmwh.12414

Reid, E. W., McNeill, J. A., Holmes, V. A., \& Alderdice, F. A. (2014). Women's perceptions and experiences of fetal macrosomia. Midwifery, 30(4), 456-463. https://doi.org/10.1016/j.midw.2013.05.007

Roberts, J. (2012). The visualised foetus: A cultural and political analysis of ultrasound imagery. Routledge.

Rouse, D. J., Owen, J., Goldenberg, R. L., \& Cliver, S. P. (1996). The effectiveness and costs of elective cesarean delivery for fetal macrosomia diagnosed by ultrasound. Journal of the American Medical Association, 276(18), 1480-1486. https://doi.org/10.1001/jama.276.18.1480

Sadeh-Mestechkin, D., Walfisch, A., Shachar, R., Shoham-Vardi, I., Vardi, H., \& Hallak, M. (2008). Suspected macrosomia? Better not tell. Archives of Gynecology and Obstetrics, 278(3), 225-230. https://doi. org/10.1007/s00404-008-0566-y 
Sanchez-Ramos, L., Bernstein, S., \& Kaunitz, A. M. (2002). Expectant management versus labor induction for suspected fetal macrosomia: A systematic review. Obstetrics and Gynecology, $100(5$ Pt 1), 997-1002. https://doi.org/10.1097/00006250-200211000-00030

Stacey, T., Thompson, J. M. D., Mitchell, E. A., Ekeroma, A. J.,

Zuccollo, J. M., \& McCowan, L. M. E. (2011). The Auckland stillbirth study, a case-control study exploring modifiable risk factors for third trimester stillbirth: Methods and rationale. Australian and New Zealand Journal of Obstetrics and Gynaecology, 51(1), 3-8. https://doi. org/10.1111/j.1479-828X.2010.01254.x

Stubert, J., Peschel, A., Bolz, M., Glass, A., \& Gerber, B. (2018).

Accuracy of immediate antepartum ultrasound estimated fetal weight and its impact on mode of delivery and outcome - a cohort analysis. BMC Pregnancy and Childbirth, 18(1), 1-8. https://doi.org/10.1186/ s12884-018-1772-7

Taylor, J. S. (2008). The public life of the fetal sonogram: Technology, consumption, and the politics of reproduction. Rutgers University Press.

Thomas, G. M., \& Lupton, D. (2016). Threats and thrills: Pregnancy apps, risk and consupmtion. Health, Risk and Society, 17(7-8), 495-509. 10.1080/13698575.2015.1127333

Thomas, G. M., Roberts, J., \& Griffiths, F. E. (2017). Ultrasound as a technology of reassurance? How pregnant women and health care professionals articulate ultrasound reassurance and its limitations. Sociology of Health and Illness, 39(6), 893-907. https://doi. org/10.1111/1467-9566.12554

Van Wagner, V. (2016). Risk talk: Using evidence without increasing fear. Midwifery, 38, 21-28. https://doi.org/10.1016/j.midw.2016.04.009

Vercellini, P., Fumagalli, M., Consonni, D., De Braud, L., Barbara,

G., Iurlaro, E., Mosca, F., \& Fedele, L. (2015). Historic cohort study on mode of delivery of a macrosomic baby: The women's point of view. Acta Obstetricia et Gynecologica Scandinavica, 94(11), 1235-1244. https://doi.org/10.1111/aogs.12723

Zhang, X., Decker, A., Platt, R. W., \& Kramer, M. S. (2008). How big is too big? The perinatal consequences of fetal macrosomia. American Journal of Obstetrics and Gynecology, 198(5), 517.e1-e6. https://doi. org/10.1016/j.ajog.2007.12.005

\section{Accepted for Publication April 2021}

Baddington, C., \& Parker, G. (2021). A weighty issue: The implications of an ultrasound prediction of a large baby in pregnancy. New Zealand College of Midwives Journal, 57, 12-19.

https://doi.org/10.12784/nzcomjnl57.2021.2.12-19 